\title{
BMJ Open Associations between hormonal contraception use, sociodemographic factors and mental health: a nationwide, register-based, matched case- control study
}

\author{
Elena Toffol (D) , ${ }^{1}$ Anna But, ${ }^{1}$ Oskari Heikinheimo, ${ }^{2}$ Antti Latvala, ${ }^{3}$ Timo Partonen, ${ }^{4}$ \\ Jari Haukka ${ }^{1,5}$
}

To cite: Toffol E, But A, Heikinheimo 0, et al. Associations between hormonal contraception use, sociodemographic factors and mental health: a nationwide, register-based, matched case-control study. BMJ Open 2020;10:e040072. doi:10.1136/ bmjopen-2020-040072

- Prepublication history and additional materials for this paper is available online. To view these files, please visit the journal online (http://dx.doi org/10.1136/bmjopen-2020040072).

Received 05 May 2020 Revised 04 September 2020 Accepted 18 September 2020

Check for updates

(c) Author(s) (or their employer(s)) 2020. Re-use permitted under CC BY-NC. No commercial re-use. See rights and permissions. Published by BMJ.

For numbered affiliations see end of article.

Correspondence to

Dr Elena Toffol;

elena.toffol@helsinki.fi

\section{ABSTRACT}

Objectives Sociodemographic and mental health characteristics are associated with contraceptive choices. We aimed to describe the sociodemographic, reproductive and mental health characteristics of all fertile-aged women in Finland who used hormonal contraception (HC) in 2017. Design A nationwide, register-based study.

Setting All women living in Finland in 2017; data from the Care Register of Health Care, Medical Birth Register, Population Register Centre, Prescription Centre, Register of Induced Abortions.

Participants All women aged 15-49 with one redeemed HC prescription in 2017 ( $n=294356)$, and a same-sized, age-matched and residence-matched, control group of non-users.

Outcomes Rates of $\mathrm{HC}$ use; associations between $\mathrm{HC}$ use and mental disorders, sociodemographic and reproductive characteristics.

Results $25.8 \%$ of women aged $15-49$ years used HC. Women with the lowest socioeconomic levels had lower odds of using $\mathrm{HC}$ than women with upper-level statuses (OR, $95 \% \mathrm{Cl}$ students: $0.97,0.94$ to 0.99 ; entitled to pension: $0.66,0.63$ to 0.69 ; other: $0.87,0.85$ to 0.89 ; unknown: $0.90,0.85$ to 0.90$)$. Women with the highest education (secondary: $1.46,1.43$ to 1.48 ; tertiary: 1.64 , 1.58 to 1.70 ; academic: $1.60,1.56$ to 1.63 ) and income (second quarter: 1.57, 1.54 to 1.60; third quarter: 1.85, 1.82 to 1.89 ; fourth quarter: $2.01,1.97$ to 2.06 ), and unmarried women had higher odds of using $\mathrm{HC}$ than women with the lowest education and income levels, and married ( $0.61,0.60$ to 0.62$)$, divorced $(0.86,0.84$ to $0.88)$, widowed $(0.73,0.65$ to 0.83$)$ or other marital status women $(0.26,0.22$ to 0.30$)$.

Parous women $(0.70,0.69$ to 0.71$)$, those with previous induced abortion(s) $(0.91,0.89$ to 0.92$)$ or recent eating $(0.68,0.62$ to 0.75$)$ or personality $(0.89,0.79$ to 0.97$)$ disorders had lower odds of $\mathrm{HC}$ use. Absolute risk differences between women with and without mental disorders ranged from $3.1 \%$ (anxiety disorders) to $10.1 \%$ (eating disorders).

Conclusions A quarter of the fertile-aged women use HC in Finland. Sociodemographic disparities persist in relation to $\mathrm{HC}$ use, although of small effect size. $\mathrm{HC}$ use is less
Strengths and limitations of this study

- Redeemed hormonal contraception (HC) prescriptions are recorded in Finnish registers from 2017 onwards, and this is the first study to examine these records for all women living in Finland.

- The studied population covers more than half of the female population of childbearing age in Finland.

- Register data with proven good validity and reliability have been used in the study.

- Records of redeemed $\mathrm{HC}$ prescriptions do not report on the actual $\mathrm{HC}$ use. It was not possible to retrieve information on young women who obtained free contraception.

- We were not able to examine contraceptive use in women with less severe psychiatric conditions.

common among women suffering from severe to moderate psychiatric disorders, especially eating disorders.

\section{INTRODUCTION}

Globally, a growing proportion of women has access to and uses contraception. While it is difficult to estimate the rates of use of less reliable methods, such as condoms and natural methods, figures based on sale records show that more than $40 \%$ of women aged 15-49 years used some type of hormonal contraception (HC) in the period 2010-2013 in the Nordic countries. Oral contraceptive (OC) pills were the preferred method (used by more than $20 \%$ of the women), followed by the levonorgestrel-releasing intrauterine system $(15 \%){ }^{1}$

Efficacy and availability of contraceptive methods, in addition to adequate policies of sexual and reproductive education and public health strategies, have resulted in a significant decline in the number of unwanted pregnancies and induced abortions in Finland, 
especially among adolescents and young women. In 2015, Finland had the lowest abortion rate among the Nordic countries, with a decline from 19.7 per 1000 women in 1973 to 8.2 in 2015. Similarly, the birth and abortion rates among adolescents aged 15-19 years declined from 10 and 15 per 1000 women in 2000 to 6 and 8, respectively, in $2015 .^{2}$ Thus, the benefits of contraceptive use seem to be related to reduced public health costs, improved women's social and work functioning, as well as better physical and mental health. ${ }^{3}$

The Nordic countries traditionally have high rates of HC use. They are also among the countries with the highest levels of welfare and social equality, as well as easy access to healthcare services, including contraception. However, disparities in the use and types of contraception continue to exist between and within countries worldwide. For example, sociodemographic and cultural factors, misconceptions and practical barriers, along with professionals' knowledge and skills influence both the women's attitude and choice, whether to use contraception and which method, as well as the prescribers' attitude and beliefs about contraceptive options. ${ }^{4-6}$ In addition, other factors that seem to be related to contraceptive use and choices are mental disorders. Disorders such as depression and anxiety are related to unintended pregnancy and risky sexual behaviour. ${ }^{78}$ Other studies have reported that women with previous or ongoing psychological symptoms, mental disorders or impulsive or antisocial behaviours typically exhibit an inconsistent use of contraception. ${ }^{9-11}$ According to other studies, the risk of unintended pregnancy is also elevated in women with eating disorders. ${ }^{12}$ However, systematic data on their HC use are still lacking, and the subject needs to be further studied. On the other hand, recent studies have reported a possible higher risk for depressive disorder and suicidal behaviour among HC users, especially adolescents. ${ }^{13} 14$

Thus, given the recent availability (from 2017) of records of redeemed HC prescriptions in Finnish registers, we identified all women of childbearing age living in Finland and using HC in 2017, with the aim to better understand the pattern of use of $\mathrm{HC}$, its underlying correlates, and its relationship to mental disorders (as indicated by a recent care episode for psychiatric disorders).

\section{METHODS}

\section{Study population}

Each individual living in Finland is given, at birth or immigration, a unique personal identification number. This number was used to select the groups of cases and controls for this study, and for the linkages between the different national registers. Cases were selected from the Prescription Centre, which is a centralised database for prescription data in the Kanta Services, ${ }^{15}$ and includes information on all prescribed and redeemed medications (including, from 2017, HC) of the population of Finland. Such information comprises the product Anatomical Therapeutic Chemical (ATC) code, ${ }^{16}$ date of prescription, prescribed amount in defined daily dose, number of prescribed packages, amount per package and date(s) of purchase.

All women living in Finland on 31 December 2017, with a record in the Prescription Centre of at least one redeemed prescription with ATC codes G02B ('contraceptives for topical use'), G03A ('HC for systemic use') or G03HB ('antiandrogens and estrogens') as of the year 2017, were identified. Further, for each HC user, a control woman, matched by year of birth and municipality of residence, with no records of redeemed HC prescriptions in 2017, was randomly selected. Selection of the groups was performed by the Social Insurance Institution of Finland (SII) and by Statistics Finland. Of the original 304993 women with at least one redeemed HC prescription in 2017, only those aged 15-49 years $(n=294445)$ were considered women of reproductive age, ${ }^{17}$ and were thus included. Since antiandrogen and oestrogen preparations, which are usually prescribed for reasons others than contraception, also exert a contraceptive effect, the 18281 women using ATC 'G03HB' preparations were included in the study. Because emergency contraception in Finland is available without prescription, the 89 women with a redeemed prescription with ATC code 'G03AD', and their matched controls, were excluded, resulting in a final population of $294356 \mathrm{HC}$ users (figure 1).

\section{Sociodemographic characteristics}

Information on sociodemographic characteristics of all the study participants on 31 December 2017 (age, municipality of residence, civil status, family type, socioeconomic group, highest level of education, occupation and annual income) was obtained through Statistics Finland from the Population Register Centre, which includes basic information of all Finnish citizens and foreign citizens permanently residing in Finland.

\section{Reproductive characteristics}

Based on the Medical Birth Register, which includes data on all live births and stillbirths since 1987, and the Register of Induced Abortions, containing data on induced abortions in Finland since 1983, we defined the following reproductive factors: parity and number of delivered children at 31 December 2016; history and number of induced abortions before 2017; and recentness of induced abortions (before 2016, 2016-2017 or no induced abortions).

Women who gave birth during 2017 were identified through the Medical Birth Register. Women who underwent a sterilisation between 1987 and 2016 were identified through the Register of Sterilisations.

\section{Mental health}

Information on mental health was retrieved from the Care Register of Health Care, which includes data on inpatient care in hospitals, health centres, day surgeries and specialised outpatient care since 1994. Specifically, discharge diagnoses with International Classification of Diseases, 10th Revision codes F10-F19 (substance abuse), 


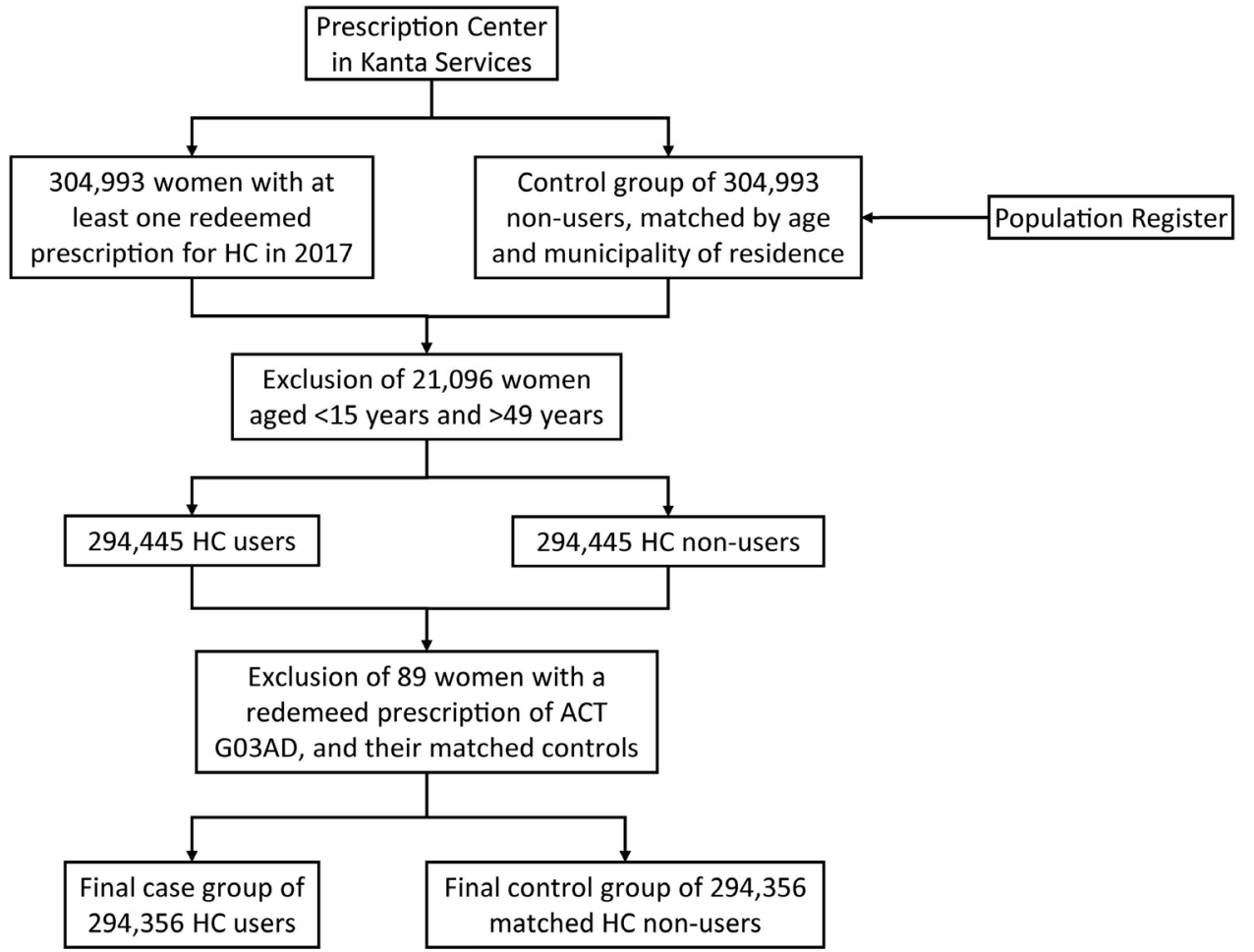

Figure 1 Selection of the study population. ATC, anatomical therapeutic chemical; HC, hormonal contraception.

F30-F39 (mood disorders), F40-F48 (anxiety disorders), F50 (eating disorders), F60 (personality disorders) and X60-X84 (intentional self-harm) in year 2016 were used to identify women with recent care episodes related to mental disorders.

\section{Patient and public involvement}

Patients and the public were not directly involved in the research process. Because this is a register-based study, no informed consent was needed.

\section{Statistical analyses}

We described the overall sample with respect to sociodemographic, reproductive and mental health characteristics using mean/median with $\mathrm{SD} / \mathrm{IQR}$ and frequencies and percentages, respectively. The prevalence of $\mathrm{HC}$ use was explored across 70 regions as defined by Statistics Finland. ${ }^{18}$

We tested whether the odds of HC use differed by sociodemographic, reproductive and mental health characteristics using univariable and progressively adjusted multivariable logistic regression models using the 'gnm' R-package, ${ }^{19}$ which allows for handling parameters of stratification factors with a large number of levels (in our case, 'municipality of residence'). Moreover, given that the use and type of contraception, ${ }^{1}$ as well as the distribution and prevalence of most of the studied predictors (eg, psychiatric disorders),${ }^{20} 21$ and their reciprocal associations, vary with age, we decided to additionally test the interaction between each predictor and age group.

Covariates in multivariable models for sociodemographic predictors consisted of all sociodemographic characteristics entered simultaneously, in addition to the age group. The interaction between each predictor and age group was tested in separate unadjusted models; if a significant interaction was found, age-stratified multivariable analyses were performed.

Multivariable models for reproductive and mental health predictors were progressively adjusted for age group, education and income level, and marital and socioeconomic status. A separate fully adjusted model further tested the interaction between age group and reproductive/mental health characteristics; if a significant interaction was found, age-stratified multivariable analyses were performed.

In order to consider the groups of women with no need of $\mathrm{HC}$, in sensitivity analyses, we excluded women who gave birth in 2017, and controlled for a history of sterilisation before 2017. Additionally, because contraception is commonly offered free-of-charge after an induced abortion, analyses were further controlled for a recent history (in 2016-2017) of abortion. The progressive adjustments for covariates are described in online supplemental table 1.

For all the analyses, the two-tailed $p$ values of $<0.05$ were considered statistically significant. All the analyses were performed with R software V.3.5.1. ${ }^{22}$

\section{RESULTS}

A total of 294356 women aged $15-49$ years $(25.8 \%$ of the Finnish female population of that age range) were HC users. Their basic characteristics are reported in table 1. Their mean age was 28.9 years (SD 8.6); $24.0 \%$ were aged 20-24 years and $6.2 \%$ aged $45-49$ years. The regional distribution of HC use by age groups is illustrated in online supplemental figure 1 . 
Table 1 Basic characteristics of women who used HC in Finland in 2017

HC users $(n=294356)$

Mean (SD)/n (\%)/median (IQR range)

Age, years

Age group*

\begin{tabular}{|c|c|c|c|}
\hline $15-19$ years & $38699(13.2)$ & 26.9 & $38699(13.2)$ \\
\hline 20-24 years & $70524(24.0)$ & 44.2 & $70524(24.0)$ \\
\hline $25-29$ years & $63824(21.7)$ & 37.1 & $63824(21.7)$ \\
\hline $30-34$ years & $44220(15.0)$ & 25.9 & $44220(15.0)$ \\
\hline $35-39$ years & $33654(11.4)$ & 19.8 & $33654(11.4)$ \\
\hline 40-44 years & $25181(8.6)$ & 15.6 & $25181(8.6)$ \\
\hline $45-49$ years & $18254(6.2)$ & 11.3 & $18254(6.2)$ \\
\hline \multicolumn{4}{|l|}{ Family type } \\
\hline Married couple with children & $74065(25.2)$ & & $96573(32.8)$ \\
\hline Married couple without children & $14337(4.9)$ & & $15277(5.2)$ \\
\hline Children with mother & $30100(10.2)$ & & $31689(10.8)$ \\
\hline Children with father & $2146(0.7)$ & & $2346(0.8)$ \\
\hline Cohabiting couple with common children & $21364(7.3)$ & & $26727(9.1)$ \\
\hline Cohabiting couple with non-common children & $5756(2.0)$ & & $5213(1.8)$ \\
\hline Cohabiting couple without children & $65559(22.3)$ & & $36898(12.5)$ \\
\hline Other & $141(0.0)$ & & $842(0.3)$ \\
\hline Missing/single & $80888(27.5)$ & & $78791(26.8)$ \\
\hline \multicolumn{4}{|l|}{ Marital status } \\
\hline Unmarried & $211461(71.8)$ & & $192428(65.4)$ \\
\hline Married & $65691(22.3)$ & & $85508(29.1)$ \\
\hline Divorced & $16507(5.6)$ & & $15239(5.2)$ \\
\hline Widowed/other & $697(0.2)$ & & $1181(0.4)$ \\
\hline \multicolumn{4}{|l|}{ Highest education level } \\
\hline Upper secondary/postsecondary non-tertiary & $142340(48.4)$ & & $134095(45.6)$ \\
\hline Short-cycle tertiary & $8187(2.8)$ & & $7229(2.5)$ \\
\hline $\begin{array}{l}\text { Academic degree (bachelor's, master's, doctoral } \\
\text { or equivalent) }\end{array}$ & $94498(32.2)$ & & $83077(28.2)$ \\
\hline $\begin{array}{l}\text { Missing (including, eg, missing information on } \\
\text { education other than of primary school level, } \\
\text { school dropouts) }\end{array}$ & $46331(16.8)$ & & $69955(23.8)$ \\
\hline \multicolumn{4}{|l|}{ Occupation } \\
\hline Employed & $210807(71.6)$ & & $178555(60.7)$ \\
\hline Unemployed & $17681(6.0)$ & & $23559(8.0)$ \\
\hline Student & $50519(17.2)$ & & $59973(20.4)$ \\
\hline Entitled to pension & $3629(1.2)$ & & $6162(2.1)$ \\
\hline Other & $11720(4.0)$ & & $26107(8.9)$ \\
\hline \multicolumn{4}{|l|}{ Socioeconomic group } \\
\hline Self-employed & 10067 (3.4) & & 10707 (3.6) \\
\hline Upper-level employees & $37170(12.6)$ & & $34810(11.8)$ \\
\hline Lower-level employees & $104874(35.6)$ & & $86036(29.2)$ \\
\hline Manual workers & $45113(15.3)$ & & $42254(14.4)$ \\
\hline Students & $56580(19.2)$ & & $63920(21.7)$ \\
\hline
\end{tabular}

Continued

HC non-users ( $\mathrm{n}=294356)$

$28.9(8.6)$

$\%$ of the corresponding

age population

$28.9(8.6)$ 
Table 1 Continued

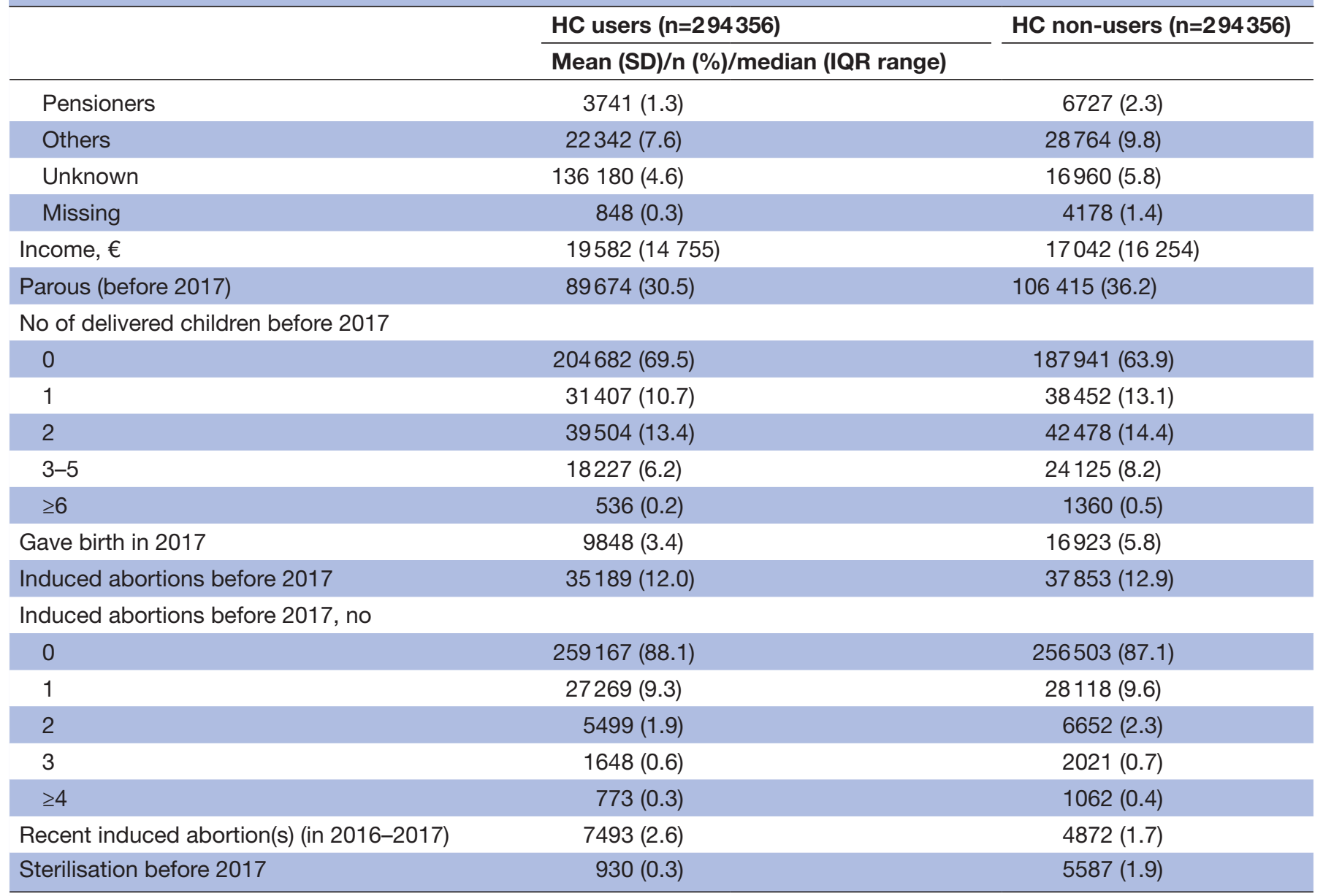

*Because the case and control groups were matched by age, age group frequencies in HC users and non-users are the same. $\mathrm{HC}$, hormonal contraception.

\section{Sociodemographic characteristics}

A greater proportion of unmarried or cohabiting women without children, compared with those of other marital statuses or family types, used HC. Additionally, a larger proportion of women with higher (upper secondary, tertiary or academic) compared with primary level education; employed as upper-level or lower-level employees or manual workers compared with self-employed people, students, those entitled to pension or of other/unknown socioeconomic status; and those with higher annual income used HC (table 1).

Women with the lowest socioeconomic levels (students, pensioners, and other and unknown levels) had lower odds of using HC compared with women with upperlevel statuses in a multivariable model simultaneously adjusting for all sociodemographic characteristics and age group. In the same model, women with the highest education and income levels and those who were not married had higher odds of using HC compared with women with the lowest education and income levels, and to those who were married, divorced, widowed or of other marital status (figure 2, online supplemental figure 2). The results did not change in sensitivity analyses.
The age group significantly interacted with socioeconomic and marital status, and education and income levels $(p<0.0001)$. Specifically, in the younger age groups (15-29 years) the proportions of HC users were low among women entitled to pensions, but high among lower-level employees and manual workers. Additionally, the proportions of HC users were especially high among women with low/secondary and academic education in young adults (20-29 years). With increasing age, HC use increased among married and widowed women, but decreased among women in the lower income quarters (see online supplemental table 1).

\section{Reproductive characteristics}

Parous women were less likely to use contraception (OR $0.70,95 \%$ CI 0.69 to $0.71, \mathrm{p}<0.0001$, in a model adjusted for age group, education, income and marital and socioeconomic status), and the odds for HC use decreased with the increasing number of children (ranging from OR $0.70,95 \%$ CI 0.69 to 0.72 for one child; to OR $0.33,95 \%$ CI 0.30 to $0.37, \mathrm{p}<0.0001$, for six or more children in the above-described adjusted 
A

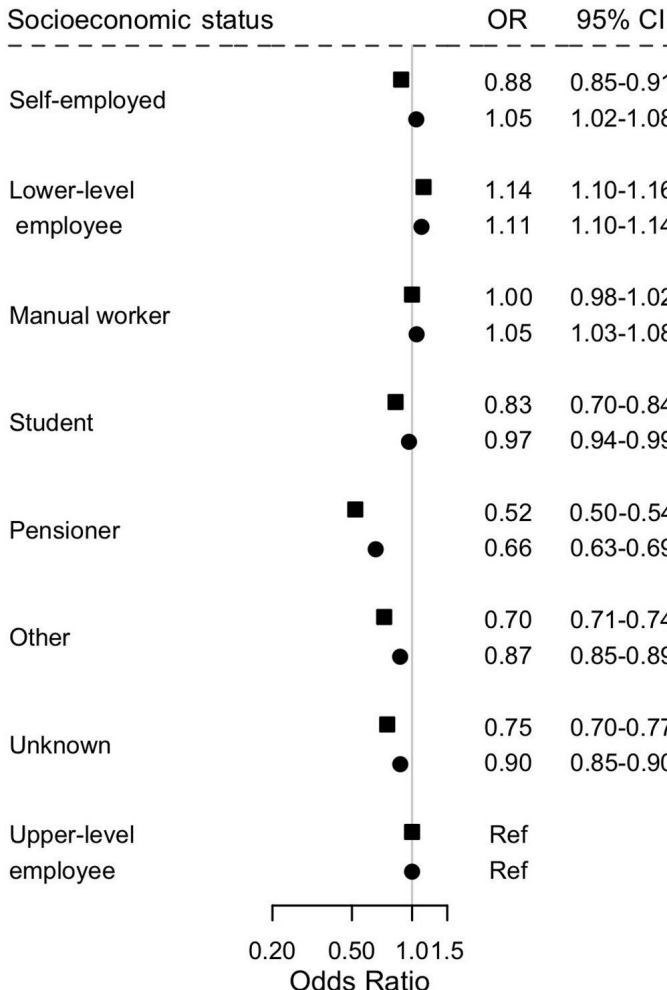

C

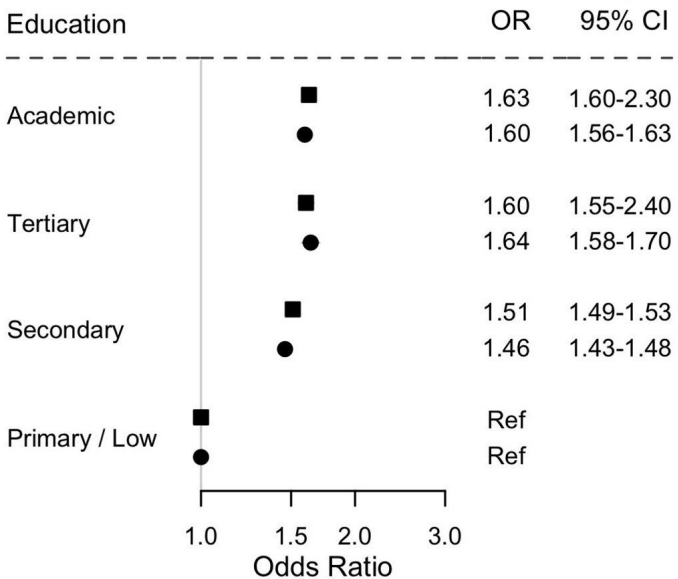

Unadjusted $\bullet$ Adjusted

B

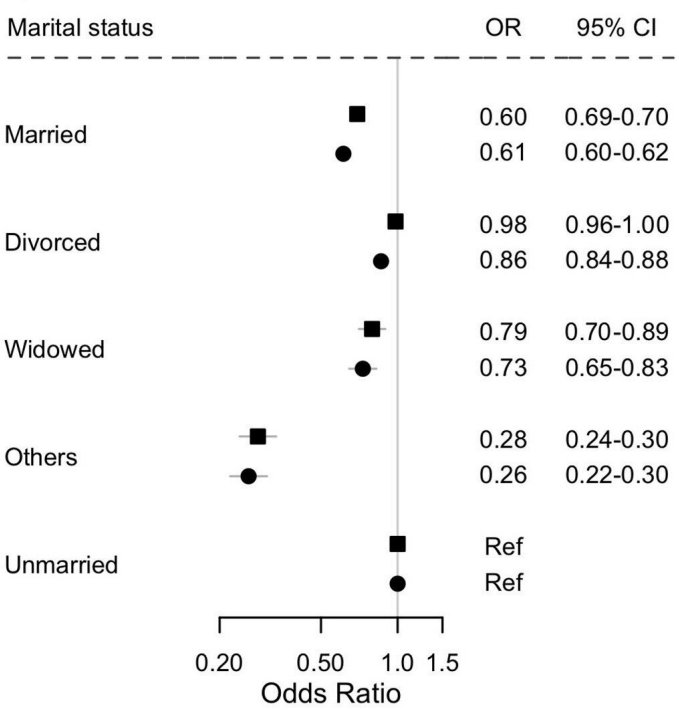

D

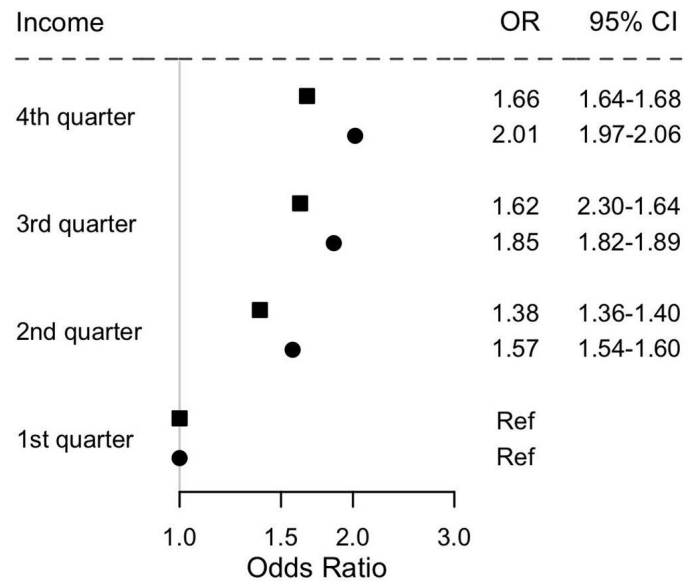

Figure 2 Associations of HC use with sociodemographic characteristics in simple and multivariable conditional regression models. All sociodemographic characteristics (marital and socioeconomic status and education and income levels) are simultaneously entered in the adjusted model, in addition to the age group. HC, hormonal contraception.

models). The proportion of HC users was especially low among young parous women (20-29 years: $37.8 \%$ vs $52.1 \%$ in non-parous women; $\mathrm{p}$ value for agexparity interaction <0.0001) (see online supplemental table 2).

Women with a history of induced abortion(s) had slightly lower odds of HC use (OR $0.91,95 \%$ CI 0.89 to $0.92, \mathrm{p}<0.0001$, in a model adjusted for age group, marital and socioeconomic status, and education and income levels); the odds decreased with increasing number of abortions, ORs ranging from 0.94 (95\% CI
0.92 to 0.95$)$ to 0.81 ( $95 \%$ CI 0.77 to $0.86, \mathrm{p}<0.0001)$ for one to three or more abortions in the same fully adjusted model. The proportion of $\mathrm{HC}$ users was higher in teenagers and young women with a history of an induced abortion, while in the older age groups (35-49 years) it was lower among women with previous abortion(s) ( $\mathrm{p}$ value for agexabortion interaction $<0.0001$ ) (see online supplemental table 2 and figure $3)$. The results did not change after excluding women who gave birth in 2017. When examining the recentness of abortion(s), the odds for using $\mathrm{HC}$ was higher 
Table 2 Prevalence of recent care episodes for psychiatric disorders in women using and not using $\mathrm{HC}$ in Finland in 2017

\begin{tabular}{lrr}
\hline & HC users & HC non-users \\
\cline { 2 - 3 } Psychiatric diagnosis & $\mathbf{n}(\%)$ & \\
\hline $\begin{array}{l}\text { Manic episode/bipolar } \\
\text { disorder }\end{array}$ & $1030(0.35)$ & $1198(0.41)$ \\
$\begin{array}{l}\text { Depressive episode } \\
\text { Recurrent depressive }\end{array}$ & $4672(1.59)$ & $5291(1.80)$ \\
disorder & $2301(0.78)$ & $2721(0.92)$ \\
Persistent mood disorder & $278(0.09)$ & $319(0.11)$ \\
Substance use & $1045(0.36)$ & $1264(0.43)$ \\
Anxiety disorders & $6048(2.06)$ & $6817(2.32)$ \\
\hline $\begin{array}{l}\text { Eating disorders } \\
\text { Personality disorder }\end{array}$ & $685(0.23)$ & $1032(0.35)$ \\
\hline Intentional self-harm & $16(0.21)$ & $864(0.29)$ \\
\hline
\end{tabular}

$\mathrm{HC}$, hormonal contraception.

among women with a recent abortion (in 2016-2017) (OR $1.60,95 \%$ CI 1.54 to $1.66, \mathrm{p}<0.0001$ ), but slightly lower among women with abortion(s) before 2016 (OR $0.97,95 \%$ CI 0.96 to $0.99, \mathrm{p}=0.0021$ ) compared with women with no such history in a fully adjusted model.

\section{Mental health}

The prevalence of care episodes due to psychiatric disorders in 2016 is reported in table 2. Differences in absolute risks for not using $\mathrm{HC}$ between women with and without a recent psychiatric care episode ranged between $3.1 \%$ (anxiety disorders) and $10.1 \%$ (eating disorders), corresponding to a difference in relative risks between $6.1 \%$ and $20.3 \%$.

Most of the associations suggestive of lower HC use among women with mental disorders were lost after adjustment for covariates (marital and socioeconomic status, education and income levels and age group). The only exception was the lower odds for HC use in women suffering from eating and personality disorders, in both unadjusted (OR 0.66, 95\% CI 0.60 to 0.73 ; and OR 0.69, $95 \%$ CI 0.63 to 0.77 , respectively) and fully adjusted models (OR 0.68, 95\% CI 0.62 to 0.75 ; and OR 0.87 ; $95 \%$ CI 0.79 to 0.97 ) (table 3 ).

We found a statistically significant interaction between age and a recent care episode due to manic episode/ bipolar disorder $(\mathrm{p}=0.0030)$, depressive episode, recurrent depressive disorder, anxiety disorders and personality disorders $(p<0.0001)$, substance abuse $(p=0.014)$ and eating disorders $(\mathrm{p}=0.0087)$. The proportions of women using $\mathrm{HC}$ were higher among women suffering from substance abuse and anxiety disorders in the younger age category (15-19years), but lower in almost all the other age groups. The prevalence of $\mathrm{HC}$ users among women with a recent care episode due to bipolar, eating or personality disorders, depressive episode or recurrent

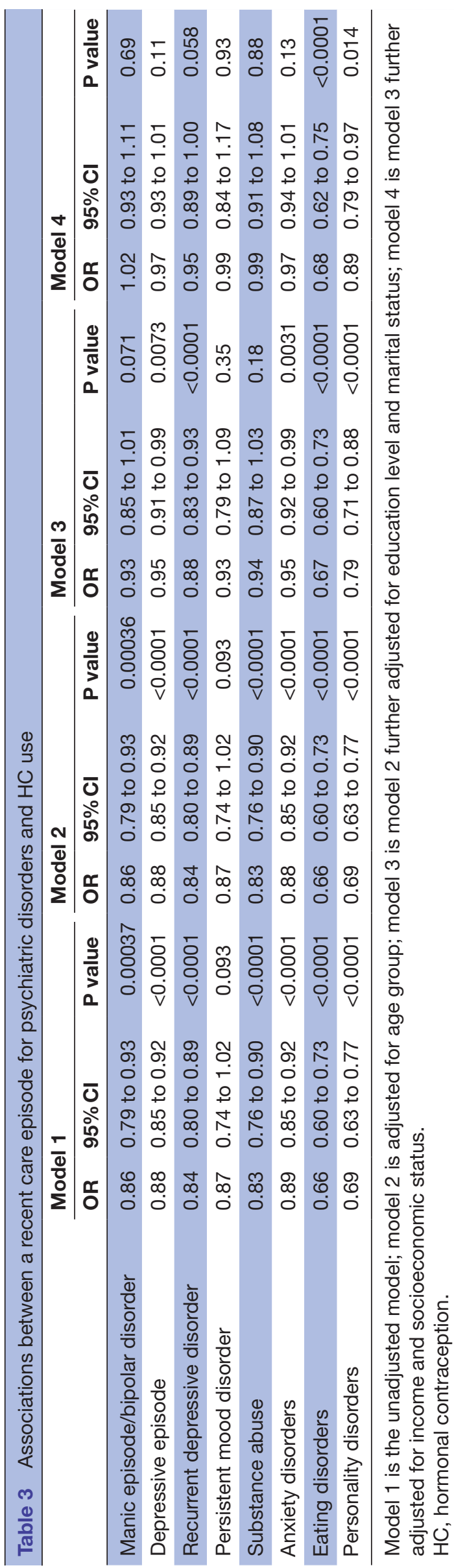


A
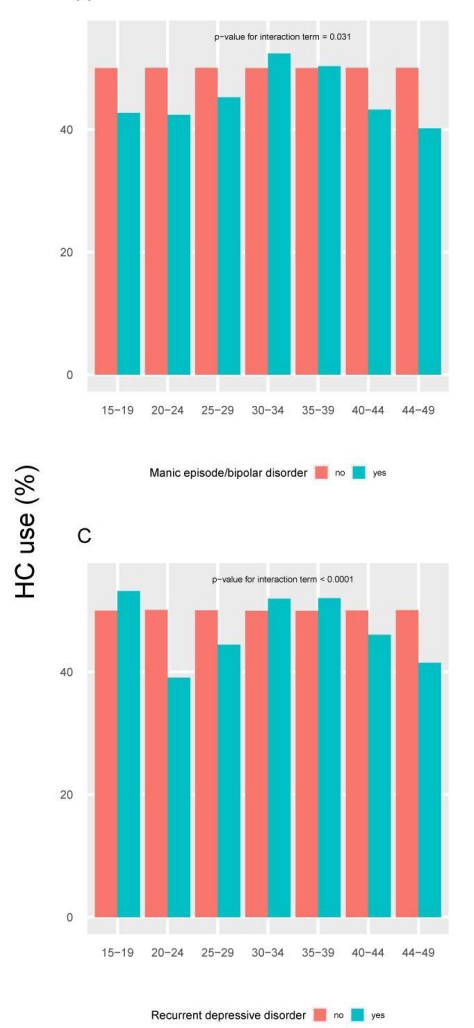

B
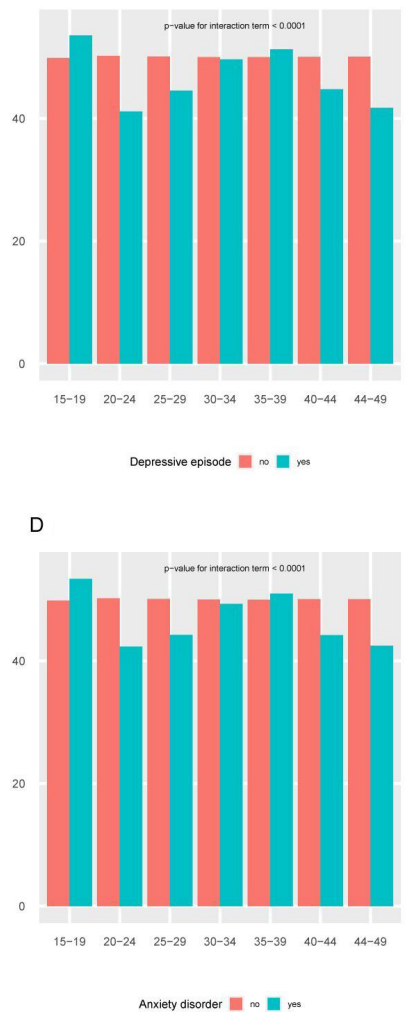

Age group (years)

Figure 3 Proportions of $\mathrm{HC}$ use among women with and without manic episode/bipolar disorder (A), depressive episode (B), recurrent depressive disorder (C) and anxiety disorder (D) diagnosis, by age group. $P$ values for the interaction term are from fully adjusted conditional models (controlled for marital and socioeconomic status and education and income levels). HC, hormonal contraception.

depressive disorder, was especially lower than in healthy women in the younger (15-29years) age groups, but higher in the middle-age groups (30-39years) for bipolar and recurrent depressive disorder (figures 3 and 4 , and online supplemental table 3 ).

In sensitivity analyses, the associations between lower HC use and a recent care episode for recurrent depressive, personality or eating disorder remained in fully adjusted models (see online supplemental table 4). We found an interaction between the age group and a recent care episode for manic episode/bipolar disorder ( $\mathrm{p}=0.0031)$, depressive episode and recurrent depressive disorder $(\mathrm{p}<0.0001)$, substance abuse $(\mathrm{p}=0.0086)$, anxiety disorders and personality disorders $(\mathrm{p}<0.0001)$ and eating disorders $(\mathrm{p}=0.024)$.

\section{DISCUSSION}

More than a quarter of the fertile-aged female population were using HC in Finland in 2017. HC users differed from non-users with respect to several sociodemographic and reproductive characteristics. Women with a recent care episode due to mental disorders tended to use HC less

A
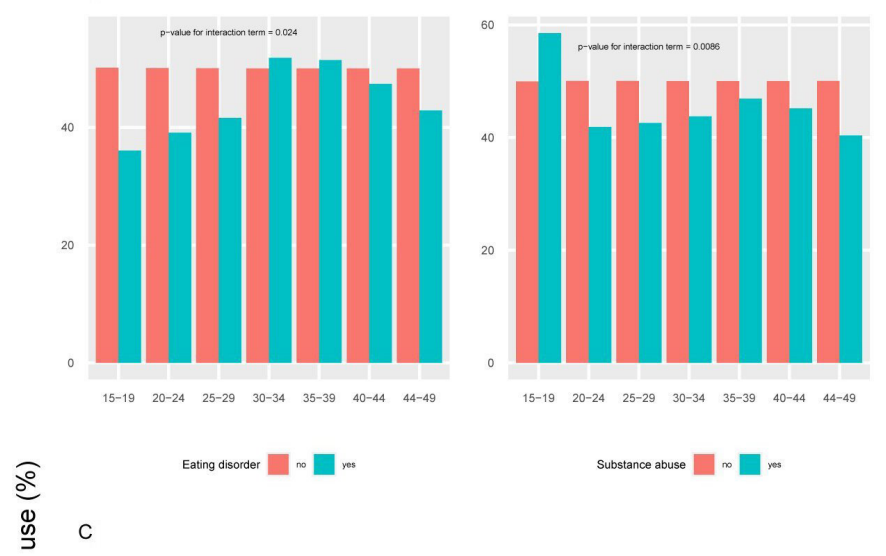

오

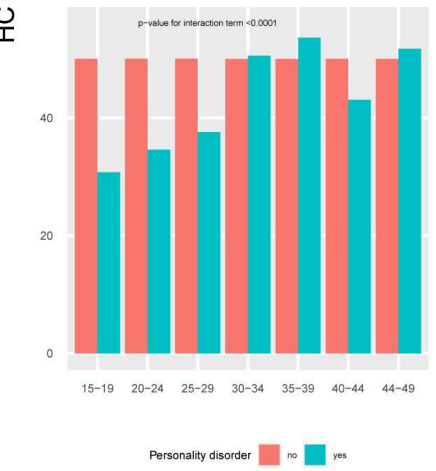

Age group (years)

Figure 4 Proportions of $\mathrm{HC}$ use among women with and without eating disorders (A), substance abuse (B) and personality disorder $(\mathrm{C})$ diagnosis, by age group. $\mathrm{P}$ values for the interaction term are from fully adjusted conditional models (controlled for marital and socioeconomic status and education and income levels). HC, hormonal contraception.

frequently than healthy women; specifically, HC use was especially low among women with a recent care episode for eating disorders and, to a lesser extent, personality disorders. However, all the observed differences were of small size, suggesting only a marginal relation to $\mathrm{HC}$ use.

The rate of HC use in Finland, as well as the proportion of $\mathrm{HC}$ users among teenage girls $(27 \%)$, are in line with those reported in other countries. ${ }^{2324}$ The use of HC seemed to decline with age, with almost $60 \%$ of all $\mathrm{HC}$ users being younger than 30 years. This figure is likely to underestimate the real proportion of teenagers and/or students using $\mathrm{HC}$ in Finland, since an increasing number of municipalities provide young women ( $<25$ years) with free contraception for a period ranging from 3 months to 1 year or longer, which is not captured by our study. A possible reason explaining the apparently low prevalence of HC use among older women is the increasing proportion of women aged 30 years and over who opt for intrauterine contraception, ${ }^{1}$ which can be used for several years after insertion, and thus are not captured by our study.

In Finland, HC users appeared to have higher median income and education levels, and to belong to higher socioeconomic groups compared with non-users. Low 
education and income levels, as well as low occupational rate and lower socioeconomic status, are well-recognised indicators of non-use and inconsistent use of HC, as well as of use of less effective contraceptive methods, such as condoms. ${ }^{25-28}$ There are probably several reasons for this pattern, such as difficulties in accessing healthcare services, unemployment or instable family relations. On the other hand, the reverse association, that is, that non-use of contraception could lead to poorer educational attainment and lower income due to a higher risk of unintended pregnancy, is likewise plausible. Partly in line with previous studies, ${ }^{28} 29$ we found that married and parous women were less likely to use HC, and the association became stronger with the increasing number of children. Again, the use of long-acting reversible contraceptive methods may explain these figures. However, the small size of the observed differences suggests that all these factors have a fairly modest effect. In addition, the overall rate of contraceptive use in Finland, as well as the proportions of $\mathrm{HC}$ users among the most disadvantaged groups (eg, women with missing/primary education or belonging to the lower socioeconomic groups) were still rather high. Interestingly, we found that women with a recent abortion, and especially those who belong to the young age group, were more likely to use HC. This is an encouraging finding, as it suggests that successful policies, postabortion care and contraception provision may have been implemented. ${ }^{30}$

Mental disorders such as depressive, substance abuse and anxiety disorders have been associated with poor contraceptive compliance, inconsistent use or non-use of contraception and use of less-effective and more userdependent methods. ${ }^{8132}$ Our study confirmed that the odds of HC use are lower among women with a recent care episode for mental disorders. People suffering from psychiatric morbidity have an elevated risk for engaging in risky sexual behaviour, ${ }^{33}$ for unintended pregnancy, ${ }^{734}$ and having an induced abortion. A survey on outpatients with mental disorders reported that more than a quarter of the sexually active women did not use contraception and $61 \%$ of pregnancies were unintended. ${ }^{35}$ In a sample of low-income women referred to family planning services, women with symptoms of depression, especially if comorbid with alcohol abuse, were more likely to choose less-effective methods or no method at all rather than hormonal methods. ${ }^{36}$ In women aged 18-20 years, depressive, anxiety or stress symptoms were associated with further non-use of contraception or use of lesseffective, user-dependent methods, ${ }^{8}$ as well as with lower proportions of consistent contraception use. ${ }^{37}$ The rate of unintended pregnancy was higher among women with stress symptoms, as well as among women with perceived moderate/high social discrimination. ${ }^{38}{ }^{39}$ In our study, age seemed to add to the associations between mental disorders and $\mathrm{HC}$ use. Indeed, teenage women with a recent care episode for anxiety disorders or substance abuse were using HC more often than their counterparts. However, this tendency reversed after 20 years of age. On the one hand, this suggests that effective psychiatric and reproductive counselling are available for teenage girls, possibly through student welfare services. The finding might also reflect successful reproductive education in high schools. Further, we speculate that young women, especially those suffering from a mental disorder, are lacking easily accessible and long-lasting mental and reproductive support after high school. However, these results have to be taken with caution. For example, the health service access/user bias could explain at least part of the findings. Indeed, women with a diagnosed mental condition are more likely to use healthcare services and become HC users. Similarly, HC users are more likely to use healthcare services and have their mental disorders diagnosed. On the other hand, the possibility that HC use may be related, in a subgroup of susceptible women, to higher vulnerability to psychiatric disorders cannot be totally ruled out. However, the effect sizes were modest, with an absolute difference ranging between 3\% and $10 \%$, which suggests that psychiatric conditions are only marginally related to contraceptive use among Finnish women of childbearing age. Rather, it is plausible that a combination of sociodemographic-related, reproductiverelated and mental health-related factors reciprocally contribute to women's contraceptive choice.

A novel finding of our study is the clearly low rate of HC use among women suffering from eating disorders. Women with eating disorders commonly have menstrual abnormalities, and may assume they are not fertile. Even if these women often have reduced fertility, they are also at higher risks of unplanned pregnancy and induced abortion compared with those with no (active) eating or other psychiatric conditions, ${ }^{12} 40-43$ possibly due to nonuse of contraception.

Our findings have public health implications. Although Finland is a country with high levels of welfare and social equalities, socioeconomic health inequalities do exist. ${ }^{44}$ Our study confirms this and calls for the implementation of strategies aimed to reduce barriers in access to contraception. Education regarding reproduction and contraception starting from primary school, easy access to family planning services for all women and couples, and refining national policies on uniform access to free contraception are some of the strategies that are being implemented. Our results point to unmet reproductive needs of women belonging to high-risk groups, such as young women with mental disorders, especially eating disorders. To date, no study has examined in detail HC use and consistency of use among these women, which highlights the importance of promoting reproductive care and contraception use among young women with these disorders. This might be done for example by strengthening the collaboration between reproductive and mental health professionals.

There are some limitations to the present study. First, a record of a redeemed HC prescription does not guarantee its actual use. However, because HC is not reimbursed by the SII, it is likely that the majority of those who purchased the drug did in fact use it. By using register 
data on redeemed prescriptions rather than medical records of prescriptions, we were able to exclude primary non-compliance. Second, we were not able to identify women who had an intrauterine device inserted in 2017 but was removed or expelled soon after insertion. Similarly, we cannot exclude that a number of women in the control group were in fact using $\mathrm{HC}$, for example because of prescriptions redeemed, or intrauterine devices or implants inserted during the previous years but were still in use in 2017. However, we were able to include in the HC user group women who had a prescription made before, but who redeemed it in 2017. Because the limitation relative to the HC-users and non-users definition similarly applies to both groups, it is likely that the introduced bias is minimal. Although pharmacy data and prescription registers are accurate and complete, ${ }^{45}$ the completeness of the present data cannot be guaranteed, because the HC records were included in the Prescription Centre only recently. Further, it was not possible to retrieve information on the real purchase of contraceptive methods that do not require a prescription or on young women who obtained free contraception as part of municipal programmes. Because data on secondary and tertiary healthcare before 2016 were not available, women with no need of HC due to history of hysterectomy could not be accounted for in the sensitivity analyses. Another limitation arises from the definition of mental disorders that are based on hospital or outpatient clinic discharge diagnoses in 2016, and as such capture only recent moderate to severe disorders. Thus, we were not able to examine contraceptive use in relation to less severe and rather prevalent psychiatric conditions. Additionally, because of the cross-sectional design of the study, it was not possible to test any hypotheses on the causality of the associations between HC use and mental disorders. Moreover, because parity was defined on the basis of delivered children as recorded in the Medical Birth Register since 1987, information for the oldest members of our cohorts (born in 1968) may be incomplete. However, this limitation likely concerns only a small number of births/ women.

Despite the above limitations, strengths of the study include the representativeness of the population, covering more than half of the female population of childbearing age, and the use of register data with proven good validity and reliability. ${ }^{46}$ By using uniform criteria across the whole study population to identify HC users, we were able to reduce the potential for information bias. Further, the possibility of interlinking multiple social and healthcare registers guaranteed extensive, valid and reliable information of the study population.

\section{CONCLUSIONS}

In Finland more than 25\% of fertile-aged women use HC (either OC or contraceptives for topical use). Sociodemographic and health disparities still exist in relation to $\mathrm{HC}$ use, although the size of their effect is rather small. New public health strategies should promote access to effective contraception among more disadvantaged women and those with moderate to severe mental disorders, including eating disorders.

\section{Author affiliations}

${ }^{1}$ Department of Public Health, University of Helsinki, Faculty of Medicine, Helsinki, Finland

${ }^{2}$ Department of Obstetrics and Gynecology, University of Helsinki and Helsinki University Hospital, Helsinki, Finland

${ }^{3}$ Institute of Criminology and Legal Policy, University of Helsinki, Helsinki, Finland ${ }^{4}$ Department of Public Health Solutions, Finnish Institute for Health and Welfare, Helsinki, Finland

${ }^{5}$ Faculty of Medicine and Health Technology, Tampere University, Tampere, Finland

Acknowledgements We wish to thank Alyce Whipp for English language editing.

Contributors $\mathrm{JH}$ contributed to the study conception; $\mathrm{ET}, \mathrm{AB}, \mathrm{OH}, \mathrm{AL}, \mathrm{TP}$ and $\mathrm{JH}$ contributed to the study planning and design, interpretation of the data, and critical revision of the manuscript. ET and $\mathrm{JH}$ had full access to the data and performed statistical analyses. ET wrote the first draft of the report. ET, AB, OH, AL, TP and JH approved the submitted version of the manuscript.

Funding This work was supported by Jane and Aatos Erkko Foundation (grant number 170062) and the Avohoidon tutkimussäätiö (Foundation for Primary Care Research).

Map disclaimer The depiction of boundaries on this map does not imply the expression of any opinion whatsoever on the part of BMJ (or any member of its group) concerning the legal status of any country, territory, jurisdiction or area or of its authorities. This map is provided without any warranty of any kind, either express or implied.

Competing interests $\mathrm{OH}$ reports grants from Helsinki University Central Hospita Research funds and grants from Finska Läkaresällskapet during the conduct of the study; personal fees from Bayer Health Care AG, personal fees from GedeonRichter, personal fees from Sandoz AG, personal fees from HRA-Pharma, and personal fees from Vifor Pharma, outside the submitted work. All other authors declare no competing interests.

Patient consent for publication Not required.

Ethics approval The study was approved by the Ethics Committee of the University of Helsinki, Faculty of Medicine (3/2018).

Provenance and peer review Not commissioned; externally peer reviewed.

Data availability statement № data are available.

Supplemental material This content has been supplied by the author(s). It has not been vetted by BMJ Publishing Group Limited (BMJ) and may not have been peer-reviewed. Any opinions or recommendations discussed are solely those of the author(s) and are not endorsed by BMJ. BMJ disclaims all liability and responsibility arising from any reliance placed on the content. Where the content includes any translated material, BMJ does not warrant the accuracy and reliability of the translations (including but not limited to local regulations, clinical guidelines, terminology, drug names and drug dosages), and is not responsible for any error and/or omissions arising from translation and adaptation or otherwise.

Open access This is an open access article distributed in accordance with the Creative Commons Attribution Non Commercial (CC BY-NC 4.0) license, which permits others to distribute, remix, adapt, build upon this work non-commercially, and license their derivative works on different terms, provided the original work is properly cited, appropriate credit is given, any changes made indicated, and the use is non-commercial. See: http://creativecommons.org/licenses/by-nc/4.0/.

ORCID iD

Elena Toffol http://orcid.org/0000-0001-6757-7355

\section{REFERENCES}

1 Lindh I, Skjeldestad FE, Gemzell-Danielsson K, et al. Contraceptive use in the Nordic countries. Acta Obstet Gynecol Scand 2017;96:19-28.

2 THL. Pohjoismaiset raskaudenkeskeytykset 2015. Aborter i Norden 2015 [online], 2015. Available: http://www.julkari.fi/handle/10024/ 132062 [Accessed 20 Mar 2019]. 
3 WHO. Family planning/contraception methods. Available: https:// www.who.int/news-room/fact-sheets/detail/family-planningcontraception [Accessed 1 Jul 2020].

4 Mosher W, Jones J, Abma J. Nonuse of contraception among women at risk of unintended pregnancy in the United States. Contraception 2015;92:170-6.

5 Black K, Lotke P, Buhling KJ, et al. A review of barriers and myths preventing the more widespread use of intrauterine contraception in nulliparous women. Eur J Contracept Reprod Health Care 2012;17:340-8.

6 Sweeney L-A, Molloy GJ, Byrne M, et al. A qualitative study of prescription contraception use: the perspectives of users, general practitioners and pharmacists. PLoS One 2015;10:e0144074.

7 Coverdale JH, Turbott SH, Roberts H. Family planning needs and STD risk behaviours of female psychiatric out-patients. $\mathrm{Br} \mathrm{J}$ Psychiatry 1997;171:69-72.

8 Hall KS, Moreau C, Trussell J, et al. Role of young women's depression and stress symptoms in their weekly use and nonuse of contraceptive methods. J Adolesc Health 2013;53:241-8.

9 Hall KS, Steinberg JR, Cwiak CA, et al. Contraception and mental health: a commentary on the evidence and principles for practice. Am J Obstet Gynecol 2015;212:740-6.

10 Bengtsdotter H, Lundin C, Gemzell Danielsson K, et al. Ongoing or previous mental disorders predispose to adverse mood reporting during combined oral contraceptive use. Eur J Contracept Reprod Health Care 2018;23:45-51.

11 Clarke JG, Hebert MR, Rosengard C, et al. Reproductive health care and family planning needs among incarcerated women. Am J Public Health 2006;96:834-9.

12 Easter A, Treasure J, Micali N. Fertility and prenatal attitudes towards pregnancy in women with eating disorders: results from the Avon longitudinal study of parents and children. BJOG 2011;118:1491-8.

13 Skovlund CW, Mørch LS, Kessing LV, et al. Association of hormonal contraception with depression. JAMA Psychiatry 2016;73:1154.

14 Skovlund CW, Mørch LS, Kessing LV, et al. Association of hormonal contraception with suicide attempts and suicides. Am J Psychiatry 2018;175:336-42.

15 Kanta Services. What are the Kanta services? Available: https://www. kanta.fi/en/about-kanta-services [Accessed 17 Feb 2020].

16 WHOCC. ATC/DDD index, 2020. Available: www.whocc.no/atc_ddd index/ [Accessed 17 Feb 2020].

17 WHO. Reproductive health indicators: guidelines for their generation, interpretation and analysis for global monitoring. Geneva: World Health Organization, 2006: 63.

18 Statistics Finland. Sub-regional units, 2019. Available: https:// www.stat.fi/meta/luokitukset/seutukunta/001-2019/index_en.html [Accessed 10 Feb 2020].

19 Turner H, Firth D. Generalized nonlinear models in R: an overview of the gnm package. R package version 1.1-1, 2020. Available: https:// cran.r-project.org/package $=$ gnm

20 Alonso J, Angermeyer MC, Bernert S, et al. Prevalence of mental disorders in Europe: results from the European study of the epidemiology of mental disorders (ESEMeD) project. Acta Psychiatr Scand Suppl 2004;420:21-7.

21 Ward ZJ, Rodriguez P, Wright DR, et al. Estimation of eating disorders prevalence by age and associations with mortality in a simulated nationally representative US cohort. JAMA Netw Open 2019;2:e1912925.

22 RStudio Team. RStudio: integrated development for R. RStudio, Inc, Boston, MA, 2019. Available: http://www.rstudio.com/

23 Daniels K, Abma JC. Current contraceptive status among women aged 15-49: United States, 2015-2017. NCHS data brief, no 327. Hyattsville, MD: National Center for Health Statistics, 2018.

24 Rotermann M, Dunn S, Black A. Oral contraceptive use among women aged 15 to 49: results from the Canadian health measures survey. Health Rep 2015;26:21-8.
25 Costas L, Sequera V-G, Quesada P, et al. Hormonal contraception and postmenopausal hormone therapy in Spain: time trends and patterns of use. Menopause 2015;22:138-46.

26 Frost JJ, Singh S, Finer LB. Factors associated with contraceptive use and nonuse, United States, 2004. Perspect Sex Reprod Health 2007;39:90-9.

27 Krings KM, Matteson KA, Allsworth JE, et al. Contraceptive choice: how do oral contraceptive users differ from condom users and women who use no contraception? Am J Obstet Gynecol 2008;198:e46-7.

28 Lucke JC, Watson M, Herbert D. Changing patterns of contraceptive use in Australian women. Contraception 2009;80:533-9.

29 Molloy GJ, Sweeney L-A, Byrne M, et al. Prescription contraception use: a cross-sectional population study of psychosocial determinants. BMJ Open 2015:5:e007794.

30 Gyllenberg FK, Saloranta TH, But A, et al. Induced abortion in a population entitled to free-of-charge long-acting reversible contraception. Obstet Gynecol 2018;132:1453-60.

31 Walsemann KM, Perez AD. Anxiety's relationship to inconsistent use of oral contraceptives. Health Educ Behav 2006;33:197-214.

32 Zink TM, Shireman TI, Ho M, et al. High-risk teen compliance with prescription contraception: an analysis of Ohio Medicaid claims. $J$ Pediatr Adolesc Gynecol 2002;15:15-21.

33 Ramrakha S, Caspi A, Dickson N, et al. Psychiatric disorders and risky sexual behaviour in young adulthood: cross sectional study in birth cohort. BMJ 2000;321:263-6.

34 James-Hawkins L, Denardo D, Blalock C, et al. Do depressive symptoms in male and female adolescents predict unintended births in emerging adulthood? Matern Child Health J 2014;18:2115-23.

35 Hauck Y, Nguyen T, Frayne J, et al. Sexual and reproductive health trends among women with enduring mental illness: a survey of Western Australian community mental health services. Health Care Women Int 2015;36:499-510.

36 Garbers S, Correa N, Tobier N, et al. Association between symptoms of depression and contraceptive method choices among low-income women at urban reproductive health centers. Matern Child Health $J$ 2010;14:102-9.

37 Stidham Hall K, Moreau C, Trussell J, et al. Young women's consistency of contraceptive use-does depression or stress matter? Contraception 2013;88:641-9.

38 Hall KS, Kusunoki Y, Gatny H, et al. The risk of unintended pregnancy among young women with mental health symptoms. Soc Sci Med 2014;100:62-71.

39 Hall KS, Kusunoki Y, Gatny H, et al. Social discrimination, stress, and risk of unintended pregnancy among young women. J Adolesc Health 2015;56:330-7.

40 Bulik CM, Hoffman ER, Von Holle A, et al. Unplanned pregnancy in women with anorexia nervosa. Obstet Gynecol 2010;116:1136-40.

41 Micali N, dos-Santos-Silva I, De Stavola B, et al. Fertility treatment, twin births, and unplanned pregnancies in women with eating disorders: findings from a population-based birth cohort. BJOG 2014;121:408-16.

42 Morgan JF, Lacey JH, Chung E. Risk of postnatal depression, miscarriage, and preterm birth in bulimia nervosa: retrospective controlled study. Psychosom Med 2006;68:487-92.

43 Linna MS, Raevuori A, Haukka J, et al. Reproductive health outcomes in eating disorders. Int J Eat Disord 2013;46:826-33.

44 Lahelma E, Pietiläinen O, Rahkonen O, et al. Social class inequalities in health among occupational cohorts from Finland, Britain and Japan: a follow up study. Health Place 2015;31:173-9.

45 Furu K, Wettermark B, Andersen M, et al. The Nordic countries as a cohort for pharmacoepidemiological research. Basic Clin Pharmacol Toxicol 2010;106:86-94.

46 Heino A, Niinimäki M, Mentula M, et al. How reliable are health registers? registration of induced abortions and sterilizations in Finland. Inform Health Soc Care 2018;43:310-9. 